\title{
Supremacy of Magnesium Chloride for Decolourisation of Textile Wastewater: A Comparative Study on the Use of Different Coagulants
}

\author{
Akshaya Kumar Verma, Puspendu Bhunia, and Rajesh Roshan Dash
}

\begin{abstract}
In this study, treatment efficiency of magnesium chloride (MgCl2.6H2O) was compared with respect to ferrous sulphate (FeSO4.7H2O), polyaluminium chloride (PACI), and aluminium chlorohydrate (ACH) for the treatment of textile wastewater. Treatment efficiency was assessed in terms of decolourisation and chemical oxygen demand (COD) reduction of synthetic textile wastewater containing reactive, direct and disperse dyes, along with the other chemical constituents that are normally released from different textile processing units. $\mathrm{MgCl}$.6H2O/Lime produced colour removal efficiency of $99.68 \%$ at a dosage $1200 \mathrm{mg} / \mathrm{L}$ for the wastewater containing all the three dyes together. $\mathrm{MgCl} 2.6 \mathrm{H} 2 \mathrm{O} / \mathrm{Lime}$ was also found to be the most effective coagulant system for treatment of textile wastewater containing only reactive dye, which produced $99.73 \%$ colour removal at a dosage of $1100 \mathrm{mg} / \mathrm{L}$. For both the direct and disperse dyes, ACH was found to be superior over $\mathrm{MgCl}$.6H2O/Lime, FeSO4.7H2O/Lime, and PACl. Industrial grade $\mathrm{ACH}$, which is normally used as polyelectrolyte, for the first time was used as coagulant in this study and was also appeared to be significant for decolourisation of textile wastewater containing all the three dyes together. From this study, $\mathrm{MgCl} 2.6 \mathrm{H} 2 \mathrm{O} / \mathrm{Lime}$ was recommended as the best coagulant for the decolourisation of textile wastewater having very high original $\mathrm{pH}$.
\end{abstract}

Index Terms-Aluminium chlorohydrate (ACH), coagulation, colour removal, magnesium chloride $\left(\mathrm{MgCl}_{2} \cdot \mathbf{6} \mathrm{H}_{2} \mathrm{O}\right)$, polyaluminium chloride (PACl), textile wastewater.

\section{INTRODUCTION}

Textile dyeing and finishing industries are one of the biggest users of potable water as well as the chemical additives during various steps of textile processing. Wastewater discharge from these industries is a major source of environmental pollution. Potential harmful direct and indirect effects of textile wastewater have also been discussed by Verma et al. [1]. Effluents from these industries generally possess very complex characteristics such as deep colour due to the presence of residual dyes, high $\mathrm{pH}$, high temperature, large amount of suspended solids (SS), high chemical oxygen demand (COD) and toxic chemicals. Direct discharge of this effluent into the water bodies or open land is undesirable not only because of its

Manuscript received January 30, 2012; revise March 6, 2012. This work was supported by the Ministry of Human Resource Development, India.

Authors are with the School of Infrasturcture, Indian Institute of Technology Bhubaneswar, Odisha, India (email: akshaya@iitbbs.ac.in; pbhunia@iitbbs.ac.in; rrdash@iitbbs.ac.in). colour, but also due to the production of carcinogenic compound from the decomposition of complex dyes. Some of these dyes are recalcitrant compounds that persist in the environment over a long period of time due their extended half-life [2]. Accumulation of colour due to residual dyes in the wastewater significantly diminishes aesthetic quality, hinders sunlight penetration, affects photosynthetic activity and disturbs the ecosystem of receiving water [3], [4]. Therefore, textile wastewater should effectively be treated to comply the legal as well as the aesthetic standards before discharging it into the environment or municipal wastewater treatment plant.

The available literature shows a large number of well established conventional decolourisation methods involving physico-chemical, chemical and biological processes, as well as some of new emerging techniques like sonochemical or advanced oxidation processes. However, there is no single economically and technically viable method to solve this problem and usually two or three methods have to be combined in order to achieve adequate level of colour removal [5], [6]. Additionally, biological processes are generally cheap, simple and environmental friendly, which can be used effectively to remove the biodegradable organics but to a very lesser extent for removal of colour due to less biodegradable nature of the textile dyes. Almost all advanced oxidation processes are associated with high cost of operation and may produce the toxic by-products. Till date, chemical coagulation/ flocculation has been widely used as one of the most practised decolourisation technology for the treatment of textile wastewater. The main advantage of conventional physico-chemical processes like chemical coagulation and flocculation is the decolourisation of wastewater takes place by removal of dye molecule from the textile wastewater, and not by the partial decomposition of dyes, which can lead to an even more potentially harmful and toxic aromatic compound [7]

Effectiveness of various metallic coagulants has been well established for treatment of textile wastewater containing a single dye or mixture of dyes of the same class with only distilled water for the preparation of synthetic textile wastewater. However, very limited studies have been reported on chemical treatment of synthetic textile wastewater containing majority of the chemical additives that are used in textile industry during different steps of textile processing. To the best of our knowledge, no study has been observed in the literature on the treatment of textile wastewater containing diverse toxic chemicals that are released from textile industries along with the mixture of different classes of dyes. Also, very limited data are 
available to assess the quantity and nature of sludge production [8]. Therefore, the present study was focused to investigate the effectiveness of Ferrous sulphate $\left(\mathrm{FeSO}_{4} \cdot 7 \mathrm{H}_{2} \mathrm{O}\right)$, Magnesium chloride $\left(\mathrm{MgCl}_{2} \cdot 6 \mathrm{H}_{2} \mathrm{O}\right)$, Polyaluminium chloride $(\mathrm{PACl})$ as well as Aluminium chlorohydrate $(\mathrm{ACH})$ as coagulants and lime as coagulant aid for the decolourisation and COD reduction of synthetic textile wastewater containing different classes of new generation dyes along with the various other chemicals. The study was focused at evaluating comparative effect of $\mathrm{pH}$ and coagulant dosage on colour removal efficiency and amount of sludge production for each of the combinations.

\section{MATERIALS AND METHODS}

\section{A. Chemicals}

Extra pure magnesium chloride $\left(\mathrm{MgCl}_{2} \cdot 6 \mathrm{H}_{2} \mathrm{O}\right)$ and ferrous sulphate $\left(\mathrm{FeSO}_{4} \cdot 7 \mathrm{H}_{2} \mathrm{O}\right)$, industrial grade (with purity $30 \% \mathrm{w} / \mathrm{w}$ ) Ployaluminium chloride $(\mathrm{PACl})$ and Aluminium chlorohydrate $(\mathrm{ACH})$ were used as coagulants and lime was used as coagulant aid. 1.0 $\mathrm{M} \mathrm{H}_{2} \mathrm{SO}_{4}$ and lime were used to adjust the desired $\mathrm{pH}$. The other chemical additives used in the preparation of the synthetic wastewater were of analytical grade.

\section{B. Synthetic Textile Wastewaters}

Synthetic textile wastewater was prepared as per the reported chemical constituents of real textile wastewater [9], [10], with a total dye concentration of $200 \mathrm{mg} / \mathrm{L}$. The total dye concentration was prepared either with a single dye, or mixing three different dyes in equal ratio along with the various chemical additives such as starch, acetic acid, sucrose, sodium carbonate, sodium hydroxide, sulphuric acid, detergent, and sodium chloride, which are used during textile processing for various purposes. Wastewaters were prepared using three commercial dyes namely, Reactive Black 5 (RB5), Congo Red (CR) and Disperse Blue 3 (DB3) in the tap water. Dyes were procured from Sigma-Aldrich, Germany.

The characteristics wavelength for each simulated dye wastewater was determined by running a scan of the dye solution on a UV-VIS spectrophotometer. The maximum absorbance wavelength $\left(\chi_{\max }\right)$ for the wastewater was found as 591, 502 and $638 \mathrm{~nm}$ respectively for RB5, CR and DB3, which was used to measure the absorbance of respective treated wastewater. Colour content of the wastewater containing mixture of dyes was determined by taking sum of the absorbencies measured at 591, 502 and $638 \mathrm{~nm}$ [11]. The characteristics of synthetic textile wastewater were: $\mathrm{COD}=1944$ to $2007 \mathrm{mg} / \mathrm{L}, \mathrm{pH}=10.4$ to $10.6, \operatorname{Abs}(591)=$ 3.1154 for the wastewater containing RB5; $\operatorname{Abs}(502)=$ 0.9264 for the wastewater containing $\mathrm{CR}$; $\operatorname{Abs}(638)=$ 0.3540 for the wastewater containing DB3; $\operatorname{Abs}(1731)=$ $\operatorname{Abs}(591)+\operatorname{Abs}(502)+\operatorname{Abs}(638)=2.3992$ for wastewater containing RB5, CR, and DB3. Percentage colour removal was determined by comparing the absorbance values for the wastewater after treatment to the absorbance value of the wastewater before treatment. Tap water served as a reference.

\section{Coagulation and Flocculation Test Procedures}

The optimum $\mathrm{pH}$ value and coagulant dosage required for efficient colour removal were determined by a jar test procedure. $1 \mathrm{~L}$ beakers, containing $500 \mathrm{~mL}$ of wastewater were used for the coagulation experiments. Lime or $1.0 \mathrm{M}$ $\mathrm{H}_{2} \mathrm{SO}_{4}$ was added to each beaker for $\mathrm{pH}$ adjustment. Chemical coagulant was added and mixed for 3 min under rapid mixing condition at $80 \mathrm{rpm}$. The solution was mixed at slow flocculation for $15 \mathrm{~min}$ at $30 \mathrm{rpm}$. After sedimentation for $20 \mathrm{~min}$, supernatants from the top of the beaker were taken for the analysis.

\section{Analyses}

Colour measurement was carried out after filtration of supernatant through Whatman No. 5 filter paper. Then, the $\mathrm{pH}$ of liquid was adjusted to about neutral. The absorbance of liquid was measured. COD was analysed as per closed reflux calorimetric method after digestion of the samples in COD reactor (Model DRB 200, HACH, USA) and then absorbance measurement was carried out by COD spectrophotometer at $600 \mathrm{~nm}$ (Model DR 2800, HACH, USA). COD standard curve was developed based on the absorbance. Sludge production (in terms of settled sludge volume) was also measured at optimised conditions for all the combinations. All the methods used for the analysis of wastewater characteristics were as per Standard Methods [12], and performed at room temperature $\left(25 \pm 5^{\circ} \mathrm{C}\right)$.

\section{RESUlTS AND DisCUSSION}

\section{A. Determination of Optimum $\mathrm{pH}$ for Chemical Coagulation of Synthetic Textile Wastewater}

In wastewater treatment using metallic coagulants, $\mathrm{pH}$ plays a very important role in determining coagulation efficiency. Therefore, experiments were designed to determine the optimum $\mathrm{pH}$ for all the combinations of synthetic textile wastewater that allowed for maximum decolourisation and COD reduction. The effect of $\mathrm{pH}$ on the treatment efficiency was examined using fixed amount of coagulant at various $\mathrm{pH}$ conditions $(4,6,8,9,10,11$, and 12) for all the coagulants. Lime and $\mathrm{H}_{2} \mathrm{SO}_{4}$ was used to adjust the desire $\mathrm{pH}$. It is well known that $\mathrm{pH}$ affects the molecular structure of the dyes, which changes the absorbance of the solution. Therefore $\mathrm{pH}$ of the untreated wastewater as well as treated wastewater was adjusted to neutral before measuring the absorbencies for evaluating the percentage of colour removal. Table I summarises the optimum $\mathrm{pH}$ for selected coagulants against various combination of dyes containing synthetic textile wastewater. Percentage colour removal increases with the increase in $\mathrm{pH}$ from 4.0 to 11.0 or 4.0 to 12.0 when $\mathrm{FeSO}_{4} \cdot 7 \mathrm{H}_{2} \mathrm{O}$ and $\mathrm{MgCl}_{2} \cdot 6 \mathrm{H}_{2} \mathrm{O}$, respectively was used as coagulants. For the combination of textile wastewater containing RB5, CR, and DB3 together, the optimal $\mathrm{pH}$ was found to be 12.0, whereas for the rest of the two combinations it was 11.0. 
TABLE I: TREATMENT EFFiCIENCY AT OPTIMISED PH FOR DiFFERENT COMBINATION OF SYNTHETIC TEXTILE WASTEWATER

\begin{tabular}{|c|c|c|c|c|c|}
\hline Coagulants & Targeted parameter & $R B 5$ & $C R$ & DB3 & $R B 5+C R+D B 3$ \\
\hline \multirow{3}{*}{$\mathrm{FeSO}_{4} .7 \mathrm{H}_{2} \mathrm{O}$} & Dosage $(\mathrm{mg} / \mathrm{L})$ & 1000 & 1000 & 1000 & 1000 \\
\hline & Optimum pH & 12 & 11 & 11 & 12 \\
\hline & Colour removal and COD reduction (\%) & $\begin{array}{c}96.14 \\
(53.31) \\
\end{array}$ & $\begin{array}{c}76.98 \\
(51.34) \\
\end{array}$ & $\begin{array}{c}78.65 \\
(36.09) \\
\end{array}$ & $\begin{array}{l}91.36 \\
(39.34)\end{array}$ \\
\hline \multirow{3}{*}{$\mathrm{MgCl}_{2} \cdot 6 \mathrm{H}_{2} \mathrm{O}$} & Dosage $(\mathrm{mg} / \mathrm{L})$ & 1000 & 1000 & 1000 & 1000 \\
\hline & Optimum pH & 12 & 11 & 11 & 12 \\
\hline & Colour removal and COD reduction (\%) & $\begin{array}{c}98.16 \\
(49.24)\end{array}$ & $\begin{array}{l}92.26 \\
(44.09)\end{array}$ & $\begin{array}{c}97.63 \\
(37.36) \\
\end{array}$ & $\begin{array}{c}93.15 \\
(59.01)\end{array}$ \\
\hline \multirow{3}{*}{ PACI } & Dosage $(\mathrm{mg} / \mathrm{L})$ & 2000 & 200 & 200 & 1500 \\
\hline & Optimum pH & 10 & 11 & 6 & 10 \\
\hline & Colour removal and COD reduction (\%) & $\begin{array}{c}64.64 \\
(55.91)\end{array}$ & $\begin{array}{c}86.00 \\
(41.86)\end{array}$ & $\begin{array}{c}96.07 \\
(56.58)\end{array}$ & $\begin{array}{c}65.60 \\
(68.53)\end{array}$ \\
\hline \multirow{3}{*}{ ACH } & Dosage $(\mathrm{mg} / \mathrm{L})$ & 600 & 200 & 50 & 500 \\
\hline & Optimum pH & 9 & 10 & 4 & 9 \\
\hline & Colour removal and COD reduction (\%) & $\begin{array}{l}45.94 \\
(37.29) \\
\end{array}$ & $\begin{array}{c}98.38 \\
(40.06) \\
\end{array}$ & $\begin{array}{c}94.78 \\
(41.32) \\
\end{array}$ & $\begin{array}{c}70.79 \\
(39.18) \\
\end{array}$ \\
\hline
\end{tabular}

$\%$ COD reduction is given within the parenthesis ( )

For all the combinations, percentage of colour removal was found to be decreasing at $\mathrm{pH}$ greater than the optimum $\mathrm{pH}$. Distinctive variation in the optimum $\mathrm{pH}$ of coagulation was observed for all the selected combinations of dye containing wastewater using pre-hydrolysed aluminium based coagulants such as $\mathrm{PACl}$ and $\mathrm{ACH}$. This confirms that the optimum $\mathrm{pH}$ of coagulation not only depends on the coagulant types but also on the nature of dyes. Unlike DB3, RB5 and CR are the dyes containing sulphate group, which enhances the precipitation of aluminium hydroxide and forms abundant amount of $\mathrm{Al}(\mathrm{OH})_{4}{ }^{-}$at alkaline $\mathrm{pH}$. However at lower $\mathrm{pH}$, aluminium based coagulant forms mostly $\mathrm{Al}(\mathrm{OH})_{3}, \mathrm{Al}(\mathrm{OH})_{2}{ }^{+}$and $\mathrm{Al}(\mathrm{OH})^{2+}$ when hydrolysed [15]. At optimum $\mathrm{pH}$, excellent reduction in colour and considerable reduction in COD was observed for the wastewater containing individual dye as well as the mixture of different dyes.

\section{B. Determination of Optimum Coagulant Dosage for} Chemical Coagulation of Synthetic Textile Wastewater

The optimum dosage of coagulants for the selected dye containing textile wastewater was determined by varying the coagulant dosage and maintaining the optimum $\mathrm{pH}$. It has already been established that lime can be used to increase the $\mathrm{pH}$ as well as it can work as a coagulant/coagulant aid due to its capability to give a certain level of colour removal [16]. Colour removal as a function of coagulant dosage is shown in Fig. 1.

It was observed in almost all the cases that percentage colour removal increases with the increase in coagulant dosage.

Above $99 \%$ colour removal efficiency was observed at $1000 \mathrm{mg} / \mathrm{L}$ of $\mathrm{MgCl}_{2} \cdot 6 \mathrm{H}_{2} \mathrm{O} / \mathrm{Lime}$ for the wastewater containing RB5. $\mathrm{FeSO}_{4} \cdot 7 \mathrm{H}_{2} \mathrm{O} / \mathrm{Lime}$ was also found to be effective which gave more than $96 \%$ colour removal efficiency at a coagulant dosage of $1200 \mathrm{mg} / \mathrm{L}$. However, considerable decrease in colour removal efficiency was observed at even higher dosage of $\mathrm{ACH}$, which still showed better efficiency as compared to $\mathrm{PACl}$ (Fig. 1a).

$\mathrm{ACH}$ and $\mathrm{PACl}$ in case of textile wastewater containing $\mathrm{CR}$ had been observed to produce complete colour removal at a coagulant dosage of 400 and $500 \mathrm{mg} / \mathrm{L}$ respectively. Excellent colour removal of more than $98 \%$ had also been observed at the higher dosage of $1300 \mathrm{mg} / \mathrm{L}$ using $\mathrm{MgCl}_{2} \cdot 6 \mathrm{H}_{2} \mathrm{O} /$ Lime and $\mathrm{FeSO}_{4} \cdot 7 \mathrm{H}_{2} \mathrm{O} /$ Lime (Fig. 1b).

Again, $\mathrm{ACH}$ in case of textile wastewater containing DB3 had been observed to give almost complete colour removal at a reduced coagulant dosage of $300 \mathrm{mg} / \mathrm{L}$. Excellent colour removal over $99 \%$ was observed at a dosage of 400 $\mathrm{mg} / \mathrm{L}$ when $\mathrm{PACl}$ was used a coagulant. However, $\mathrm{MgCl}_{2} \cdot 6 \mathrm{H}_{2} \mathrm{O} / \mathrm{Lime}$ and $\mathrm{FeSO}_{4} \cdot 7 \mathrm{H}_{2} \mathrm{O} /$ Lime was also found to be produce approximately similar degree at a colour removal at a dosage of $1000 \mathrm{mg} / \mathrm{L}$ and $1300 \mathrm{mg} / \mathrm{L}$ respectively (Fig. 1c).
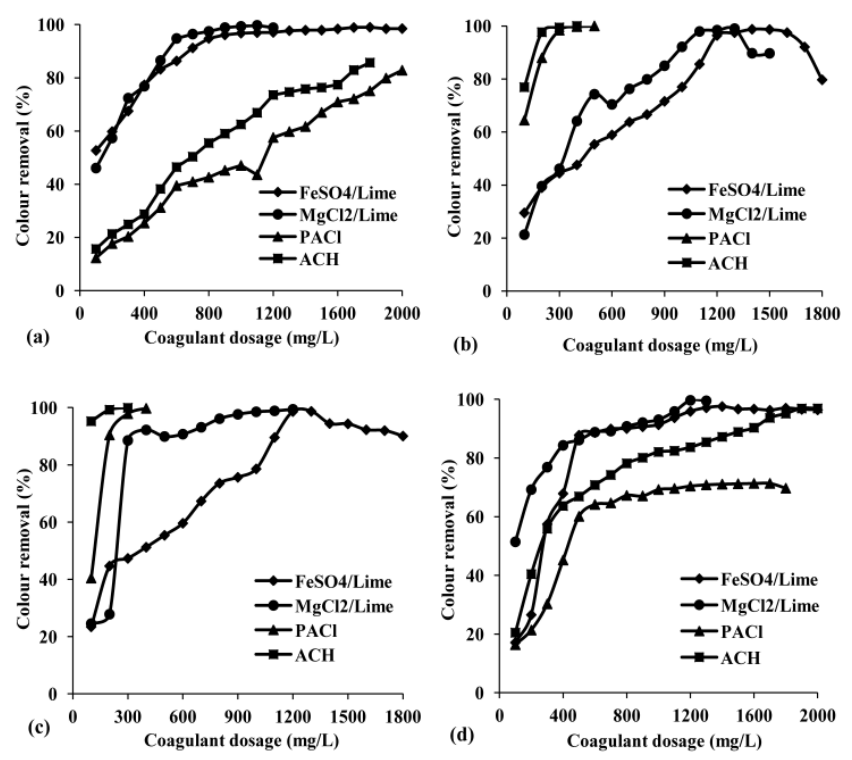

Fig. 1. Effect of coagulant dosage on the colour removal for synthetic textile wastewater containing (a) RB5 (b) CR (c) DB3 (d) RB5+CR+DB3

Colour removal efficiency of $99.68 \%$ and $97.11 \%$ had been achieved at $1300 \mathrm{mg} / \mathrm{L}$ of $\mathrm{MgCl}_{2} \cdot 6 \mathrm{H}_{2} \mathrm{O} / \mathrm{Lime}$ and $\mathrm{FeSO}_{4} .7 \mathrm{H}_{2} \mathrm{O} /$ Lime respectively, for the wastewater containing RB5, CR and DB3 together. Approximately, 97\% colour removal had also been observed at the ACH dosage of $2000 \mathrm{mg} / \mathrm{L}$. However, PACl had been observed to give very low colour removal even at extreme dosage of 1800 $\mathrm{mg} / \mathrm{L}$ (Fig. 1d). It was also observed during analysis that presence reactive dye in the mixture of dye wastewater affects the treatment efficiency of almost all the coagulants. 
This can be attributed by the well established fact that reactive dyes are more difficult to decolourise.

The experimental results revealed that, comparatively reduced coagulant dosage is required for the decolourisation of the wastewater containing disperse dye as compared to the reactive and direct dye. This can be explained and linked by the fact that disperse dyes are least soluble in nature and hence competitively more efficient to adsorb onto the hydroxide precipitates. Moreover, pre-hydrolysed metallic salts namely $\mathrm{ACH}$ and $\mathrm{PACl}$ were found to be very promising for the decolourisation of wastewater containing DB3 and CR. This might be due to the better surface adsorption of disperse and direct dyes to the polyneuclear species of aluminium hydroxides. $\mathrm{MgCl}_{2} \cdot 6 \mathrm{H}_{2} \mathrm{O} / \mathrm{Lime}$ and $\mathrm{FeSO}_{4} \cdot 7 \mathrm{H}_{2} \mathrm{O} /$ Lime were capable to give excellent decolourisation of the wastewater containing RB5. Further, more than $99 \%$ colour removal efficiency was observed for almost all the combinations of wastewater at only 1200 $\mathrm{mg} / \mathrm{L}$ of $\mathrm{MgCl}_{2} \cdot 6 \mathrm{H}_{2} \mathrm{O} / \mathrm{Lime}$. Based upon the results of this study, $\mathrm{MgCl}_{2} \cdot 6 \mathrm{H}_{2} \mathrm{O} /$ Lime can be proposed as the best coagulant combination to decolourise the textile wastewater.

Similar trends of COD reduction were observed with increasing coagulant dosage as obtained in case of colour removal for all the combinations of synthetic textile wastewater using $\mathrm{FeSO}_{4} \cdot 7 \mathrm{H}_{2} \mathrm{O} / \mathrm{Lime}, \mathrm{MgCl}_{2} \cdot 6 \mathrm{H}_{2} \mathrm{O} / \mathrm{Lime}$, $\mathrm{PACl}$ and $\mathrm{ACH}$ (Fig. 2). A maximum of $62.02 \% \mathrm{COD}$ reduction was observed at the optimum coagulant dosage of $1200 \mathrm{mg} / \mathrm{L} \quad \mathrm{MgCl}_{2} \cdot 6 \mathrm{H}_{2} \mathrm{O} /$ Lime for the wastewater containing all three dyes together (Fig. 2d). Highest COD reduction of $70.32 \%$ had been observed at extreme $\mathrm{PACl}$ dosage of $1800 \mathrm{mg} / \mathrm{L}$. Significant COD reduction was also obtained for remaining combinations of synthetic textile wastewater using $\mathrm{FeSO}_{4} .7 \mathrm{H}_{2} \mathrm{O} / \mathrm{Lime}$ and $\mathrm{ACH}$ as shown in Fig. 2.
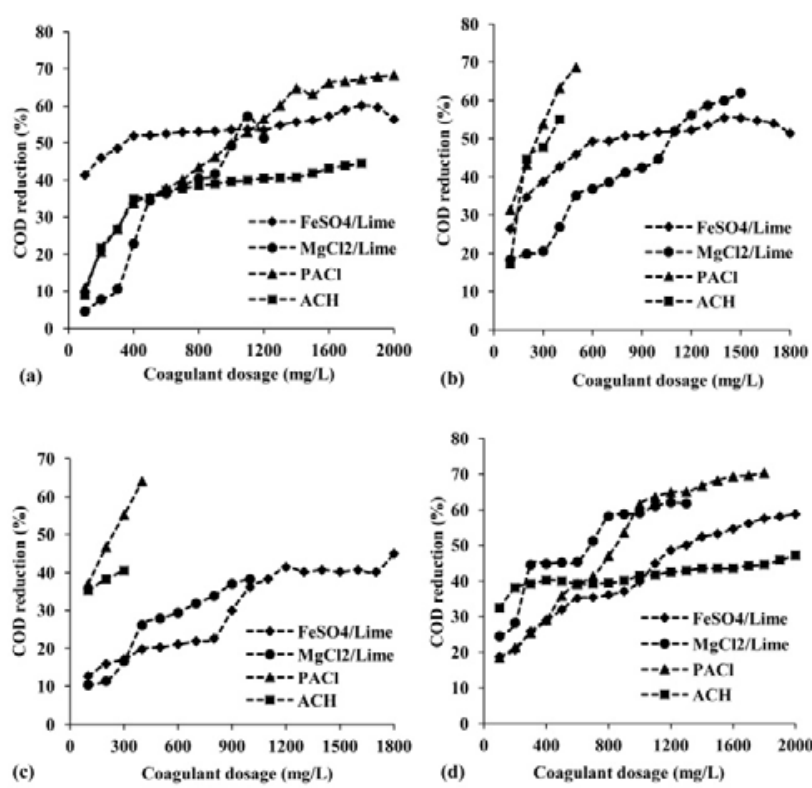

Fig. 2. Effect of coagulant dosage on the COD reduction for synthetic textile wastewater containing (a) RB5 (b) CR (c) DB3 (d) RB5+CR+DB3

Comparatively, $\mathrm{PACl}$ was observed as the better coagulant than $\mathrm{MgCl}_{2} \cdot 6 \mathrm{H}_{2} \mathrm{O} / \mathrm{Lime}, \mathrm{FeSO}_{4} \cdot 7 \mathrm{H}_{2} \mathrm{O} /$ Lime and $\mathrm{ACH}$ for $\mathrm{COD}$ reduction. This can be explained by the fact that the pre-hydrolysed nature of $\mathrm{PACl}$ forms relatively stable polyneuclear hydroxide flocs even at moderately alkaline conditions [15]. These flocs are instrumental in leading to sweep coagulation mechanism in the presence of bicarbonate alkalinity and thereby results in better COD reduction than that of other coagulation mechanisms such as charge neutralisation and adsorption. Further, COD reduction capability of $\mathrm{MgCl}_{2} \cdot 6 \mathrm{H}_{2} \mathrm{O} / \mathrm{Lime}$ was found to be lying in between $\mathrm{PACl}$ and $\mathrm{FeSO}_{4} \cdot 7 \mathrm{H}_{2} \mathrm{O}$ / Lime for all the combinations of textile wastewater except the synthetic textile wastewater containing all three dyes together. Out of selected coagulants, ACH showed the lowest COD reduction efficiency for all the combinations of wastewater.

\section{Sludge Production}

The amount and characteristics of the sludge produced during coagulation/ flocculation depends upon the type of coagulant used and the operating conditions [17]. Therefore, sludge production was measured at optimised $\mathrm{pH}$ and at optimum coagulant dosage for all the combinations. It was measured based upon the volume occupied by the flocs in $500 \mathrm{~mL}$ of sample volume after settling for $1 \mathrm{~h}$ in the Imhoff cone. A maximum of $120,88,85$ and $25 \mathrm{~mL}$ settled sludge $/ 500 \mathrm{~mL}$ of sample was observed in case of $\mathrm{FeSO}_{4} .7 \mathrm{H}_{2} \mathrm{O} / \mathrm{Lime}, \mathrm{ACH}, \mathrm{PACl}$ and $\mathrm{MgCl}_{2} \cdot 6 \mathrm{H}_{2} \mathrm{O} / \mathrm{Lime}$ respectively, for the wastewater containing $\mathrm{CR}$. $\mathrm{PACl}$ and $\mathrm{ACH}$ was observed to produce similar amount of sludge which was still lower as compared to $\mathrm{FeSO}_{4} \cdot 7 \mathrm{H}_{2} \mathrm{O} / \mathrm{Lime}$. Increased amount of sludge production in case of $\mathrm{PACl}$ and ACH as compared to $\mathrm{MgCl}_{2} \cdot 6 \mathrm{H}_{2} \mathrm{O} /$ Lime can also be linked to the purity of these compounds.

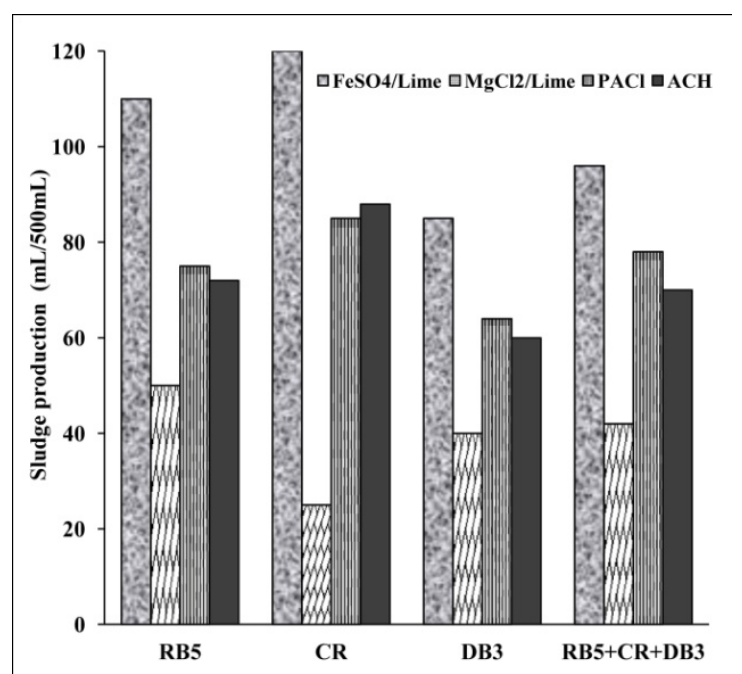

Fig. 3. Sludge production at optimised conditions for various combinations of synthetic textile wastewater

For all the combinations, volume of sludge produced was less when $\mathrm{MgCl}_{2} \cdot 6 \mathrm{H}_{2} \mathrm{O} /$ Lime was used as coagulant (Fig. 3). Maximum $50 \mathrm{~mL}$ settled sludge $/ 500 \mathrm{~mL}$ of sample was observed for the wastewater containing RB5. Significantly reduced sludge production using $\mathrm{MgCl}_{2} \cdot 6 \mathrm{H}_{2} \mathrm{O}$ may be explained by the fact that it shows very high adsorption for the dyes, particularly for direct dyes, and other chemical additives and thereby produces more compact sludge as compare to the $\mathrm{FeSO}_{4} .7 \mathrm{H}_{2} \mathrm{O} / \mathrm{Lime}, \mathrm{PACl}$ and $\mathrm{ACH}$. The results of the present study are in good agreement with the findings reported by Bidhendi et al. [8]. 


\section{Analysis of Spectrogram and Colour Removal} Mechanism of the Coagulants

Spectral analysis and investigation of colour removal mechanisms were performed for wastewater containing RB5, $\mathrm{CR}$ and DB3 dyes. All the three combinations showed almost the same trends for all the four coagulant systems ( $\mathrm{FeSO}_{4} \cdot 7 \mathrm{H}_{2} \mathrm{O} / \mathrm{Lime}, \mathrm{MgCl}_{2} \cdot 6 \mathrm{H}_{2} \mathrm{O} / \mathrm{Lime}, \mathrm{PACl}$, and $\left.\mathrm{ACH}\right)$. Therefore, wastewater containing RB5 against FeSO ${ }_{4} \cdot 7 \mathrm{H}_{2} \mathrm{O} / \mathrm{Lime}$ and $\mathrm{MgCl}_{2} \cdot 6 \mathrm{H}_{2} \mathrm{O} /$ Lime were selected to explain the spectrogram and colour removal mechanism. The spectral analysis was examined on untreated and treated wastewater at optimum $\mathrm{pH}$ and coagulant dose (shown in the Fig. 1a). The results are shown as the curve "a" for untreated wastewater and "c" for treated wastewater, respectively in Fig. 4(i) and Fig. 4(ii). It was found that the wastewater after treatment did not show any distinctive dye peaks in the visible wavelength range from 400 to $700 \mathrm{~nm}$ in both the cases. This indicates that the dye from wastewater was transferred into the hydroxide precipitate obtained by coagulation-flocculation. Further, precipitates were filtered and acidified to convert into the solution. The filtrate is then neutralised and analysed by spectrophotometer, and the results are shown as the curve "b" in Fig. 4(i) and Fig. 4(ii). It can be seen that the shapes of curve "a" and "b" appear to be almost similar and also the peaks have been observed to form at the same wavelength for both the cases. The color of neutralised solution was same as the untreated wastewater but absorbance value was less. This might be due to the fact that the complete conversion of the precipitate into the solution by acidification is almost impossible. Hence, it can be said that the removal of colour by coagulation was merely a physical phenomenon. There was no chemical change of dye molecules before, and after the coagulation as both the peaks have been found at the same wavelength for "a" and "b". The analysis is in good agreement with the observation reported by Gao et al. [16].
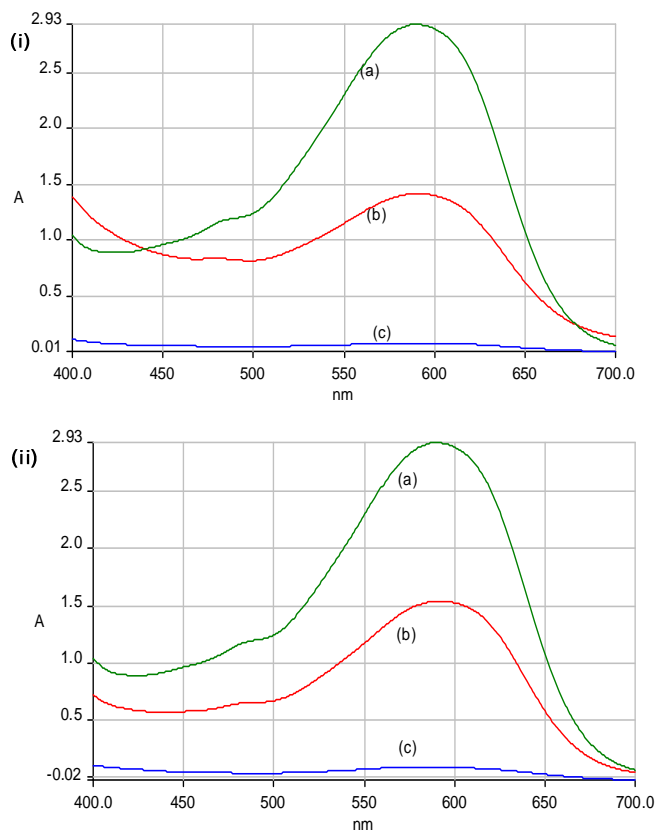

Fig. 4. The spectrogram of RB5 at optimum conditions using (i) $\mathrm{MgCl} 2.6 \mathrm{H} 2 \mathrm{O} / \mathrm{Lime}$ and (ii) $\mathrm{FeSO} 4.7 \mathrm{H} 2 \mathrm{O} / \mathrm{Lime}$ ["a": Untreated wastewater, "b": After sludge digestion and neutralisation, "c": Treated wastewater]
On the basis of the findings of this study, colour removal mechanisms of ferrous sulphate and magnesium chloride can be described as: (i) the metal ions from the coagulants first get converted into their insoluble metal hydroxides at $\mathrm{pH}$ greater than 11.0, (ii) these complex and insoluble structures of hydroxides provide a large adsorptive surface area and positive superficial surface charge leading to adsorption and charge neutralisation, (iii) finally, due to the presence of bicarbonate ions, lime reacts to form calcium carbonate precipitates, which remove dyes through the sweeping flocs mechanism [18]. Therefore, it can be said that the removal of colour using ferrous sulphate and magnesium chloride as coagulant and lime as coagulant aid takes place predominantly by adsorption and charge neutralization along with the sweep flocculation principle. Colour removal mechanism of $\mathrm{PACl}$ and $\mathrm{ACH}$ is not well understood and therefore, sweep flocculation is thought to be the principle coagulation mechanism due to the formation of huge amount of flocs at the increasing dosage of coagulant [19].

\section{CONCLUSIONS}

Decolourisation and COD reduction efficiency of coagulants significantly depends upon the $\mathrm{pH}$ of wastewater. Pre-hydrolysed coagulants such as $\mathrm{PACl}$ and $\mathrm{ACH}$ were found to be effective in decolourising the wastewaters containing direct and disperse dyes. Further, magnesium chloride in combination with lime was found to be the best over the other coagulants for decolourisation and COD reduction of textile wastewater containing all the three dyes together. In the present study, a maximum of more than $99 \%$ decolourisation efficiency and 62\% COD reduction efficiency was observed for treating synthetic textile wastewater containing a total $200 \mathrm{mg} / \mathrm{L}$ of reactive, direct and disperse dyes along with other chemical additives by using $\mathrm{MgCl}_{2} \cdot 6 \mathrm{H}_{2} \mathrm{O} /$ Lime as coagulants. Reduced sludge production and excellent color removal makes $\mathrm{MgCl}_{2} \cdot 6 \mathrm{H}_{2} \mathrm{O} /$ Lime a novel and attractive coagulant system, especially for the textile wastewater having very high original $\mathrm{pH}$. Hence, $\mathrm{MgCl}_{2} \cdot 6 \mathrm{H}_{2} \mathrm{O} /$ Lime may be recommended as an efficient coagulant system for the treatment of textile wastewater, which removes dyes by the dual mechanisms of adsorption and charge neutralization along with the sweep flocculation. Since, the system can reduce a maximum COD of approximately $60 \%$, the remaining COD will be more than that of the safe discharge standards set by the Environmental Pollution Authority of different countries. Therefore, the secondary treatment is required to take care of the rest of the organic matters to meet the safe discharge standards.

\section{FutURE SCOPE OF RESEARCH}

Future experiments are required to minimize the $\mathrm{MgCl} 2.6 \mathrm{H} 2 \mathrm{O}$ dose by combining with some natural coagulants or coagulant aids. ACH was also appeared as a very promising coagulant for decolourisation of the textile wastewater containing direct and disperse dyes, at a very less dosage. The effectiveness and coagulation mechanism 
of this coagulant is yet to be established. Therefore, it is required to conduct more and more research work on the coagulation mechanism of this coagulant.

\section{ACKNOWLEDGEMENT}

The authors would like to acknowledge the funding received from Ministry of Human Resource Development, India for carrying out research work in the related area.

\section{REFERENCES}

[1] A. K. Verma, R. R. Dash, and P. Bhunia, "A review on chemical coagulation/flocculation technologies for removal of colour from textile wastewaters," Journal of Environmental Management, vol. 93, pp. 154-168, 2012.

[2] O. J. Hao, H. Kim, and P. C. Chang, "Decolorization of wastewater," Critical Reviews of Environmental Science and Technology, vol. 30, pp. 449-505, 2000.

[3] D. Georgiou, A. Aivazidis, J. Hatiras, and K. Gimouhopoulos, "Treatment of cotton textile wastewater using lime and ferrous sulfate," Water Research, vol. 37, pp. 2248-2250, 2003.

[4] B. Merzouk, K. Madani, and A. Sekki, "Using electrocoagulationelectroflotation technology to treat synthetic solution and textile wastewater, two case studies". Desalination, vol. 250, pp. 573-577, 2010.

[5] S F. Kang and M.C. Chen, "Coagulation of textile secondary effluents with fenton's reagent," Water Science and Technology, vol. 36 (12), pp. 215-222, 1997.

[6] T. Robinson, G. Mcmullan, R. Marchant, and P. Nigham, "Remediation of dyes in textile effluent: a critical review on current treatment technologies with proposed alternatives," Bioresource Technology, vol. 77, pp. 247-255, 2001

[7] V. Golob, A. Vinder, and M. Simonic, "Efficiency of coagulation/flocculation method for treatment of dye bath effluents," Dyes and Pigments, vol. 67, pp. 93-97, 2005.

[8] G. R. N. Bidhendi, A. Torabian, H. Ehsani, and N. Razmkhah, "Evaluation of industrial dyeing wastewater treatment with coagulants and polyelectrolyte as a coagulant aid," Iran. J. Environ Health Sci. Eng., vol. 4, pp. 29-36, 2007.

[9] N. Daneshvar, A. Oladegaragoze, and N. Djafarzadeh, "Decolorization of basic dye solutions by electrocoagulation: an investigation of the effect of operational parameters," J. Hazard. Mater., vol. 129, pp. 116-122, 2006.

[10] L. Szpyrkowicz, C. Juzzolino, and S. N. Kaul, "A comparative study on oxidation of disperse dyes by electrochemical process, ozone, hypochlorite and Fenton Reagent," Water Research, vol. 35, pp. 2129-2136, 2001.

[11] B. Y. Gao, Y. Wang, Q. Y. Yue, J. C. Wei, and Q. Li, "Color removal from simulated dye water and actual textile wastewater using a composite coagulant prepared by ployferric chloride and polydimethyldiallylammonium chloride," Sep. Purif. Technol., vol. 54, pp. 157-163, 2007.

[12] APHA. Standard Methods for the Examination of Water and Wastewater, eighteenth ed., American Public Health Association, American Water Works Association, Water Pollution and Control Federation. Washington, D.C. 1998.

[13] A. Arslan, and I. A. Balcioglu, "Degradation of Remazol Black B dye and its simulated dyebath wastewater by advanced oxidation processes in heterogenous and homogeneous media," Color. Technol., vol. 117, pp. 38-42, 2001.

[14] B. H. Tan, T. T. Teng, and A. K. M. Omar, "Removal of dyes and industrial dye wastes by magnesium chloride," Water Res., vol. 34 (2), pp. 597-601, 2000.

[15] J. Gregory,and J. M. Duan, "Hydrolyzing metal salts as coagulants", Pure and Applied Chemistry, vol. 73, pp. 20172026, 2001.

[16] B. Y. Gao, Q. Y. Yue, Y. Wang, and W. Z. Zhou, "Color removal from dye-containing wastewater by magnesium chloride," J. Environ Manage., vol. 82, pp. $167172,2007$.

[17] O. S. Amuda, and I. A. Amoo, "Coagulation/flocculation process and sludge conditioning in beverage industrial wastewater treatment," $J$. Hazard. Mater. vol. 141, pp. 778-783, 2007.

[18] L. Semerjian, and G. M. Ayoub, "High-pH-magnesium coagulationflocculation in wastewater treatment," Adv. Environ. Res., vol. 7, pp. 389-403, 2003.

[19] J. Gregory and V. Dupont, "Properties of flocs produced by water treatment coagulants", Water Science and Technology, vol. 44, pp. 231-236, 2001. 